DIW BERLIN

Discussion

Papers

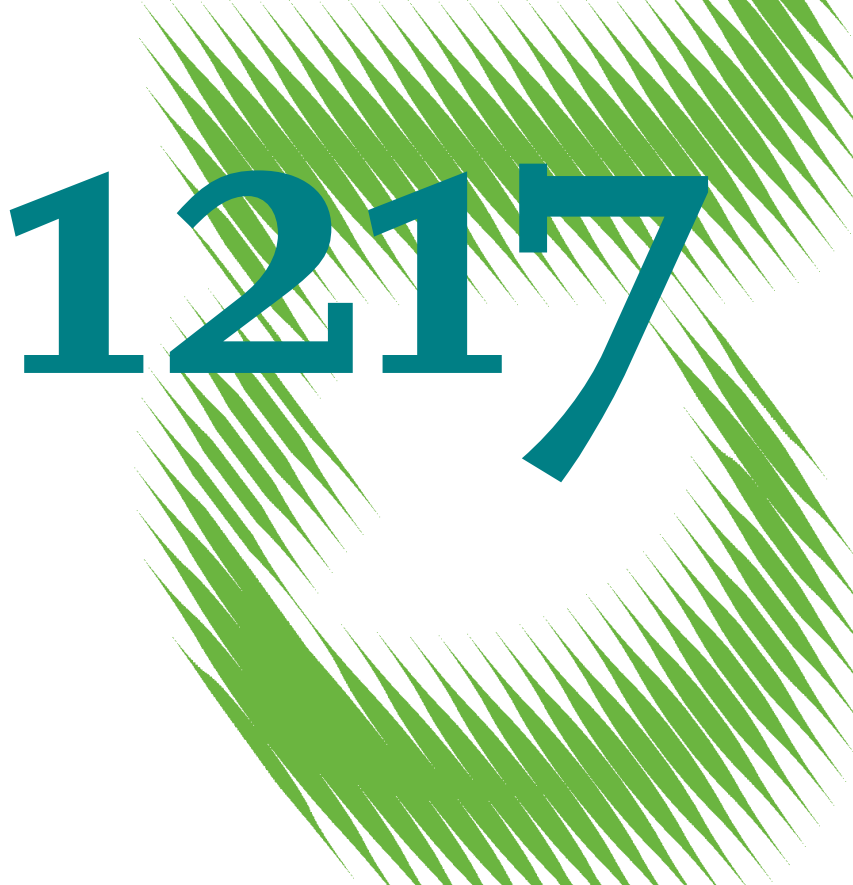

Is Technical Progress Sectorally Concentrated?

An Empirical Analysis for Western European Countries 
Opinions expressed in this paper are those of the author(s) and do not necessarily reflect views of the institute.

IMPRESSUM

(C) DIW Berlin, 2012

DIW Berlin

German Institute for Economic Research

Mohrenstr. 58

10117 Berlin

Tel. $+49(30) 89789-0$

Fax +49 (30) $89789-200$

http://www.diw.de

ISSN print edition $1433-0210$

ISSN electronic edition 1619-4535

Papers can be downloaded free of charge from the DIW Berlin website:

http://www.diw.de/discussionpapers

Discussion Papers of DIW Berlin are indexed in RePEc and SSRN:

http://ideas.repec.org/s/diw/diwwpp.html

http://www.ssrn.com/link/DIW-Berlin-German-Inst-Econ-Res.html 


\title{
Is technical progress sectorally concentrated? An empirical analysis for Western European countries
}

\author{
Alexander Schiersch ${ }^{\ddagger}$, Heike Belitz ${ }^{\ddagger}$, Martin Gornig ${ }^{\S}$ \\ ‡ German Institute for Economic Research, Germany \\ $\S$ German Institute for Economic Research and TU Berlin, Germany
}

June, 2012

\begin{abstract}
Previous research based on the growth accounting approach shows that technical progress at the industry level is more localized in continental European countries than in Anglo-Saxon countries. We use EU KLEMS data to decompose sectoral productivity for nine European countries, by means of a Malmquist approach, in order to separate technical change. Applying Harberger diagrams, we describe the sectoral patterns of technical progress. The analysis reveals that in most European countries technological progress is much more evenly distributed across sectors than Total Factor Productivity.
\end{abstract}

JEL: 014, O47, E23

Keywords: Total Factor Productivity, Generalized Malmquist Productivity Index, sectoral technical change 


\section{Introduction}

Central tools for judging the competitiveness of nations are various kinds of productivity measures. Focusing primarily on labor productivity and Total Factor Productivity (TFP), the main finding is that there are different growth patterns and a persistent divergence in productivity between nations. Yet, the reasons for this finding differ. Analyzing labor productivity, Enflo and Hjertstrand (2009), Färe et al. (2006), Henderson and Russell (2005), Kumar and Russell (2002) and Maudos et al. (2000) find capital accumulation and, if included in the analysis, human capital accumulation to be the main drivers of labor productivity growth and its divergence between countries.

Another main driver of growth and productivity differences identified in most studies is technical change. This holds, regardless of the underlying assumptions of the models used and estimation techniques applied (Ark, O'Mahony and Timmer 2008, Badunenko, Henderson and Zelenyuk 2008, Margaritis, Färe and Grosskopf 2007, Krüger 2003). However, already Balassa (1964) and Samuelson (1964), with their two-sector models, point to sectoral differences in production. Hence, in order to explain growth and productivity differences a more detailed view is appropriate. Yet, few papers address the issue of sectoral differences.

Looking at industrialized countries, Arcelus and Arozena (1999) are among the first to pursue a disaggregated approach. They analyze TFP growth for 14 OECD countries and the two sectors of manufacturing and services for the 1970 to 1990 period by means of the Generalized Malmquist Productivity Index (Griffel-Tatje and Lovell 1999). This allows decomposing TFP into technological change, efficiency improvements and scale changes. They find that, overall TFP growth in the manufacturing sector is driven more or less equally by technical progress and efficiency improvements. In contrast, the source of TFP growth in the service industry is almost always technological progress. Yet, they do not focus on the important finding of unequal distribution of technological progress and productivity between the manufacturing and service sectors within countries.

Inklaar and Timmer (2007) are the first which provide a deeper insight on these sectoral disparities of technological changes. They analyze the pattern of TFP growth in the tradition of growth accounting at the two-digit industries level. It uses Harberger diagrams (Harberger 1998) to compare sectoral growth patterns for four Anglo-Saxon countries and three continental European countries for the 1995 to 2003 period. They find that, firstly, overall TFP growth rates for the four Anglo-Saxon countries are significantly higher. Secondly, TFP growth at the industry level diverges significantly in European countries and is more 'mushroom' like. In contrast, growth rates within the Anglo-Saxon countries are more balanced or 'yeasty', as they term it (Inklaar and Timmer 2007). Timmer et al. (2011) confirm this result for the 1995 to 2005 period. Thus, a main finding of these analyses is that technological change is more broadly based in Anglo-Saxon countries, while in continental European countries it is confined to few industries. For Europe, this would imply that technology diffusion between sectors is hampered with negative impacts for long term growth. However, TFP growth in this framework is a residual which is regularly regarded as a proxy for technological change. 
Hence, already Inklaar and Timmer (2007) note that this residual includes, in addition to changes in technology, changes in economies of scale, organizational changes and 1,001 other causes (Harberger 1998, 5).

The contribution of our paper is to go further into the question: Is technological progress still unevenly distributed across sectors within European nations when accounting for economies of scale and inefficiencies? To this end we combine the approaches of Inklaar and Timmer (2007) and Arcelus and Arozena (1999). First, we dispense the growth accounting approach, which ascribes any change to technology by definition, and use the Malmquist approach, which allows us to decompose TFP. Then we follow Inklaar and Timmer (2007) and use the Harberger method in a second step to examine whether the distributional differences, with respect to TFP, can also be found for the technology component.

Given that the previous Malmquist literature mostly finds that the technology component explains most of the TFP growth, we expect to find the same in this analysis. This also implies that, if we find TFP growth unevenly distributed in a country, one can expect a rather similar distribution in the technology component. In this case, the findings by Inklaar and Timmer (2007) and Timmer et al. (2011) really point to a sectorally uneven distribution of technological progress. Yet, our results are contrary to their findings. Our analysis shows that in almost all European countries technological progress is much more evenly distributed across sectors than TFP. Hence, technical change seems to be widespread also in Europe.

The remainder of the paper is organized as follows. The next section presents an overview of the applied methods, while the data are introduced in the third section. The results of the analysis are the subject of the fourth section. First, we compare the TFP in the tradition of growth accounting with the estimated TFP by means of the GMPI approach for nine Western European countries to reveal the correlation. Second, we apply Harberger diagrams to the TFP as well as to its components to verify whether there are sectoral disparities and whether they can be also found for the technical component of the TFP. The last section concludes.

\section{Methodology}

In order to combine the approaches of Inklaar and Timmer (2007) with Arcelus and Arozena (1999), we first estimate Total Factor Productivity (TFP) using the Generalized Malmquist Productivity Index (GMPI). Then we use the Harberger diagrams to analyze the pattern of TFP growth and its components in each country. Subsequently, we briefly describe the Data Envelopment Analysis (DEA), which is needed to estimate the distance functions that are used to calculate TFP by means of GMPI. Thereafter the GMPI and its components are introduced. ${ }^{1}$ Finally, we briefly explain the idea behind the Harberger diagrams and what one can learn from it.

\footnotetext{
A brief discussion of the assets and drawbacks of the method is provided in Appendix.
} 


\section{Data Envelopment Analysis}

Data Envelopment Analysis is a nonparametric approach to examine the efficiency of any decision making unit (DMU). It is based on the idea of a production set and its enveloping production function (Farrell 1957) and became popular with the work of Charnes et al. (1978). The method lets the data define the location and shape of the production function (best practice frontier) and derives the (in)efficiency of any unit by measuring the distance of each observation to the frontier. ${ }^{2}$

Hence, we define a production possibility set $S^{t}=\left\{\left(x^{t}, y^{t}\right): x^{t}\right.$ can produce $\left.y^{t}\right\}$, itself defined by the input vector $x^{t} \in \mathfrak{R}^{N+}$ and the output vector $y^{t} \in \mathfrak{R}^{M+}$ of any DMU in the sample at time $t=1, \ldots, T$. It contains all possible input-output combinations. Choosing an output orientated approach, the frontier of $S^{t}$ is given by $\partial P^{t}\left(x^{t}\right)=\left\{y^{t}: y^{t} \in P^{t}\left(x^{t}\right), \lambda y^{t} \notin P^{t}\left(x^{t}\right), \lambda>1\right\}$. The magnitude of inefficiency of each unit is calculated according to Shephard (1970) as:

$$
D^{t}\left(x^{t}, y^{t}\right)=\min \left\{\theta: y^{t} / \theta \in P^{t}\left(x^{t}\right)\right\}=\left[\max \left\{\theta:\left(\theta y^{t}\right) \in P^{t}\left(x^{t}\right)\right\}\right]^{-1}
$$

with $D^{t}\left(x^{t}, y^{t}\right) \leq 1 .^{3}$ Thus, each observation is labeled as efficient and evaluated with a distance function of 1 if it's defining the frontier. If $D_{i}^{t}\left(x_{i}^{t}, y_{i}^{t}\right)$ is below 1 the DMU is considered as inefficient since it would be possible to produce $1 / D_{i}^{t}\left(x_{i}^{t}, y_{i}^{t}\right)$ times more outputs using the same amount of inputs. The actual calculation of each distance function is conducted by linear optimization.

\section{Generalized Malmquist Productivity Index}

As shown by Färe et al. (1994), the DEA distance functions can be applied in calculating productivity changes with the Malmquist Productivity Index (MPI). The use of this index for productivity analyses dates back to Caves et al. (1982), which proved the identity between the Törnquist Productivity Indices and the Malmquist Index. However, the components of the MPI are potentially biased in the presence of variable return to scale as shown by GriffelTatje and Lovell (1995). To overcome this problem they derived the Generalized Malmquist Productivity Index (GMPI) such that scale changes are included in the estimation of productivity changes (Griffel-Tatje and Lovell 1999, 1997). Productivity growth between $t$ and $t+1$ is now given by:

$$
\operatorname{GMPI}^{t}\left(x^{t}, y^{t}, x^{t+1}, y^{t+1}\right)=M^{t}\left(x^{t}, y^{t}, x^{t+1}, y^{t+1}\right) \operatorname{RES}^{t}\left(x^{t}, y^{t}, x^{t+1}\right)
$$

with:

2 A detailed discussion of the DEA, its underlying assumptions and the properties of its estimators can be found in Simar and Wilson (2005). We also recommend Coelli et al. (2005) for readers interested in the method.

3 In this paper the notation without any further subscript always denote distance functions calculated under the assumption of variable returns to scale. If constant returns to scales are assumed we indicate this by the subscript $c$ as in $D E$. Moreover, the subscript $t$ at each component indicates the year of the underlying technology. 


$$
\begin{array}{rlc}
\operatorname{RES}^{t}\left(x^{t}, y^{t}, x^{t+1}\right) & = & \frac{D_{c}^{t}\left(x^{t+1}, y^{t}\right) / D^{t}\left(x^{t+1}, y^{t}\right)}{D_{c}^{t}\left(x^{t}, y^{t}\right) / D^{t}\left(x^{t}, y^{t}\right)} \\
M^{t}\left(x^{t}, y^{t}, x^{t+1}, y^{t+1}\right) & = & D^{t}\left(x^{t+1}, y^{t+1}\right) / D^{t}\left(x^{t}, y^{t}\right) \\
& = & \operatorname{TEF}\left(x^{t}, y^{t}, x^{t+1}, y^{t+1}\right) \times T C H\left(x^{t+1}, y^{t+1}\right) \\
\operatorname{TEF}^{t}\left(x^{t}, y^{t}, x^{t+1}, y^{t+1}\right) & = & D^{t+1}\left(x^{t+1}, y^{t+1}\right) / D^{t}\left(x^{t}, y^{t}\right) \\
\operatorname{TCH}^{t}\left(x^{t+1}, y^{t+1}\right) & = & D^{t}\left(x^{t+1}, y^{t+1}\right) / D^{t+1}\left(x^{t+1}, y^{t+1}\right)
\end{array}
$$

Hence, the productivity change between $t$ and $t+1$ can be decomposed into three components. The scale changes, measured by the scale index $R S E^{t}$, contribute positively to productivity growth if a contraction (expansion) in the region of decreasing (increasing) returns to scale occurred. Or the other way around, it takes values less 1, if the production volume increases (decreases) in the region of decreasing (increasing) returns to scale. The $R S E^{t}$ equals 1 if the DMU did not change its scale position between $t$ and $t+1$. The second component is the efficiency index $T E F^{t}$. It measures how a DMU is catching up to its more productive competitors, if it does so. Consequently, it takes values greater than (equal to, less than) one and contributes positively (not, negatively) to productivity changes, if the efficiency of any DMU increased (did not changed, decreased) between $t$ and $t+1$. The third component captures technical changes as a shift in the productions function. Technological change is defined as the change in the location of the production function within the production possibility set. The technology index $T C H^{t}$ takes values greater than (equal to, less than) one if technical change occurred and thus more (the same, less) output can be produced in $t+1$ by the same amount of inputs as in $t$. To create these indices, six linear optimization problems need to be solved per observation and point in time to generate the distance functions.

\section{Visualizing growth patterns: The Harberger Diagrams}

Following the approach of Inklaar and Timmer (2007), we apply the Harberger diagrams to visualize growth pattern. The main idea of the diagrams is to plot the sectors in such a way that one can see their contribution to overall growth. This is achieved by ordering the sectors according to their TFP growth. The growth rates are weighted with the sector-share of valueadded and aggregated. The resulting cumulative contribution of the industries is plotted against the cumulative share of the industries (Harberger 1998). The figure contains the sectors with the highest growth rates near the origin and the sectors with the slowest or even decreasing TFP growth at the upper end of the curve. The last point on this curve is equal to the (weighted) average growth in a country.

The resulting curve must be concave due to the initial sorting. Yet, the concavity depends on the distribution of growth across industries. If all sectors show the same TFP growth, the curve would be a straight line from the origin to the average TFP growth at the upper end. The more the growth rates differ, the more concave the curve would be and thus the larger the area between the curve and the diagonal line from the origin to the average growth rate. Finally, the concavity also depends on the weight of the sectors. If the sectors with the highest growth 
are rather small, in terms of their relative value added, the curve will be more concave as if the sectors would be larger.

The interpretation of the curve and the area under the curve is as follows: If the growth is more broad-based, the curve is close to the diagonal line und the area under the curve is small (see Figure 1). Harberger calls this "yeasty" since growth is evenly as the growth of bread that is caused by yeast (Harberger 1998). Hence, TFP growth in a country is driven by many, if not all, sectors. In the growth accounting framework this also means that all sectors more or less equally participate in technical progress. However, if growth can be found only in few sectors, the curve will be much more convex and more like a "Mushroom" (Harberger 1998). In this case, the area between the diagonal line and the curve will be larger than in the yeasty case (see Figure 1). In the growth accounting framework this would imply that technical progress in a country rely on few sectors and many sectors do not contribute to technological progress. In the context of this paper the Harberger diagrams mainly show whether growth is evenly or unevenly distributed. The interpretation regarding technological progress applies only when we look at the technology component of the GMPI.

Figure 1: Examples for Harberger diagrams ${ }^{4}$

mushroom pattern

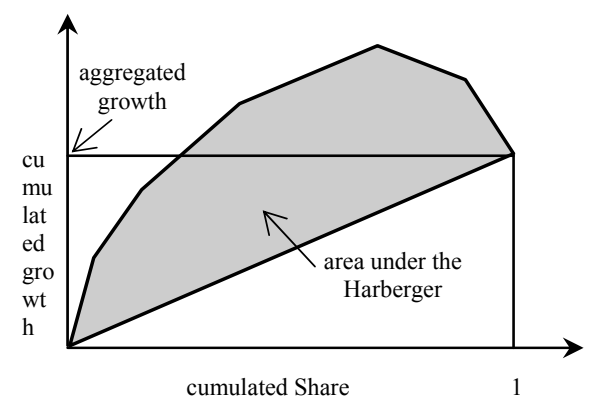

yeasty patter

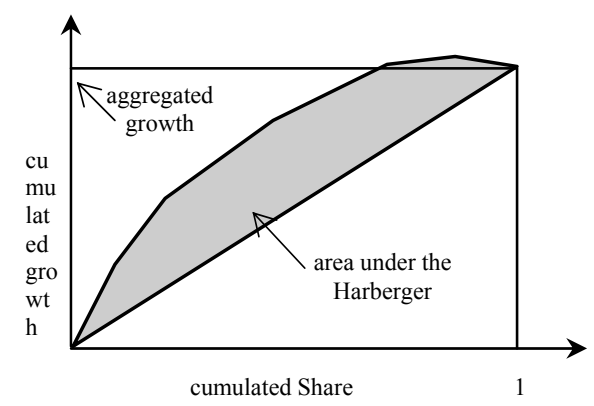

\section{Data}

The analysis is conducted using data from the EU KLEMS data base, which originates from an international research project supported by the European Commission as part of the $6^{\text {th }}$ Framework Program. ${ }^{5}$ It provides data for 25 EU-Countries ${ }^{6}$, the USA, Japan, Australia, Canada and Korea at a sectoral subdivision of 72 industries until 2005. Although we have data for some of these countries since 1970 we restrict the analysis to the period 1995 to 2005 in order to include as many countries as possible. The origins of the data are, similar to the STAN data base of the OECD, national accounts. Additionally, EU KLEMS includes national labor market-, industry- and capital-census data. According to O'Mahony und Timmer (2009) this

4 The Figure is, slightly modified, taken from Inklaar and Timmer (2007).

5 The interested reader is referred to O'Mahony und Timmer (2009) for a detailed discussion of the EU KLEMS data base.

6 Romania and Bulgaria are not in the sample. 
makes the EU KLEMS data base in parts richer than STAN, especially with respect to the level of sectoral subdivision, the volume of labor and capital services. The data base also provides TFP growth rates calculated using growth accounting according to Jorgenson et al. (1987).

We used labor (hours worked) and capital (capital services) as inputs and value added as output to calculate TFP growth with DEA and GMPI. Capital and value added is given as nominal values in national currencies and hence need to be converted into real values. This is done by first applying purchasing power parities, provided by the OECD. It gives us nominal values in PPP\$ and they are therefore deflated in a second step, again using OECD data. Since labor is given as total hours worked, this variable needs no conversion. The bottleneck, however, is capital. We only have capital data for 15 countries between 1995 and 2005 and thus our sample is restricted to those countries. ${ }^{7}$ Although we are only interested in the Western European countries, all available data, i.e. all countries, are included in the DEA estimations in order to reduce the bias that is caused by sample reductions. ${ }^{8}$ Further, the analysis focuses on the service and industry sectors (business economy) and neglects both the public and agricultural sectors.

Besides calculating sectoral TFP growth rates we also use the TFP growth rates reported in EU KLEMS in order to compare the distribution of sectoral TFP growth rates used in Inklaar and Timmer (2007) with the ones calculated by means of the GMPI. Note, however, that that country TFP growth rates, labeled GA-TFP in this study, are not identical to those reported in the EU KLEMS database for total industry (code: "TOT"). The reason is lack of sectoral data. Comparing the distributions of TFPs requires focusing on sectors for which both, the GATFPs and GMPI-TFPs are available in order not to compare apples with pears. However, TFP estimates in the EU KLEMS database (GA-TFP) are often available only for aggregate sectors (for instance sector $\mathrm{O}$ instead of the two-digit levels 90 to 93). At the same time, TFP estimates by means of the Malmquist approach (GMPI-TFP) are calculated at the two-digit sector level because of the assumption of a common production function. Yet, EU KLEMS do not report capital and labor data for each two-digit sector and as a result, TFP growth cannot be estimated for some sectors by means of GMPI. As a consequence, we sometimes have no TFP observations (GA-TFP) at the two-digit sector level in EU KLEMS (for instance sector 90 to 93) as well as not enough calculated TFPs (GMPI-TFP) to derive an aggregated TFP that has a match in EU KLEMS (for sectors 90 to 93 in order to aggregate them into sector O). Hence, we have to omit some sectors, depending on the actual data availability in each country, when computing country level TFP-growth rates. This causes our country GA-TFPs to differ from the ones reported in EU KLEMS for total industry (code: “TOT”).

\footnotetext{
These are: Australia, Austria, Czech Republic, Denmark, Finland, Germany, Great Britain, Italia, Japan, Korea, Netherlands, Portugal, Slovenia, Sweden and the USA.

8 See the discussion of assets and drawbacks of the methods in the Appendix.
} 


\section{Results}

We analyze the sectoral concentration and distribution of productivity growth and especially of its component 'technological change' between 1995 and 2005 for nine Western European countries. In particular we analyze whether technical progress in European countries is more localized in few sectors - thus 'mushroom-like' - or if it is more broad-based - thus 'yeasty'. We apply the nonparametric Generalized Malmquist Index (GMPI) approach to derive TFP estimates and to identify sources of TFP growth at sector level by decomposing it. In order to compare our results with those of Inklaar and Timmer (2007), we also use the TFP estimates of the EU KLEMS database. These TFP estimates were calculated following a basic growth accounting framework ('GA') by Jorgenson et al. (1987). For a better differentiation we call these TFP estimates 'GMPI-TFP' and 'GA-TFP'.

As pointed out above, we calculate the TFP using a different method than Inklaar and Timmer (2007) or Timmer et al. (2011). Therefore, the first step in the analysis is to check whether both measures, the GMPI-TFP and the GA-TFP, are approximately similar. However, we do not expect identical values since the methods both differ and also rely on different assumptions. This expectation is confirmed when we consider the first and second column of Table 1 . Except for Sweden and Finland, the pure numbers differ significantly. Yet, the values are highly correlated.

Table 1: TFP growth rates and the growth rates of the GMPI-TFP components, $1995-2005^{9}$

\begin{tabular}{lcc|ccc}
\hline \hline & $(1)$ & $(2)$ & $(3)$ & $(4)$ & $(5)$ \\
Country & GA-TFP & GMPI-TFP & $\begin{array}{c}\text { technical change } \\
(\mathrm{TCH})\end{array}$ & $\begin{array}{c}\text { efficiency change } \\
(\mathrm{TEF})\end{array}$ & $\begin{array}{c}\text { scale change } \\
(\text { RES })\end{array}$ \\
\hline & & & & & \\
Austria & $0.20 \%$ & $0.38 \%$ & $1.48 \%$ & $-1.02 \%$ & $-0.08 \%$ \\
Denmark & $-0.21 \%$ & $0.28 \%$ & $0.86 \%$ & $-0.47 \%$ & $-0.11 \%$ \\
Finland & $0.99 \%$ & $0.99 \%$ & $0.82 \%$ & $0.23 \%$ & $-0.05 \%$ \\
Germany & $0.56 \%$ & $0.92 \%$ & $1.47 \%$ & $-0.33 \%$ & $-0.21 \%$ \\
Italy & $-0.48 \%$ & $-0.95 \%$ & $1.54 \%$ & $-2.18 \%$ & $-0.31 \%$ \\
Netherlands & $0.65 \%$ & $1.72 \%$ & $1.62 \%$ & $0.17 \%$ & $-0.08 \%$ \\
Portugal & $-0.85 \%$ & $0.12 \%$ & $0.81 \%$ & $-0.70 \%$ & $0.00 \%$ \\
Sweden & $0.80 \%$ & $0.80 \%$ & $1.35 \%$ & $-0.48 \%$ & $-0.07 \%$ \\
United Kingdom & $0.57 \%$ & $1.77 \%$ & $1.04 \%$ & $0.74 \%$ & $-0.01 \%$ \\
\hline \hline SOurce: EU KLEMS & & &
\end{tabular}

Source: EU KLEMS Database for GA-TFPs

Moreover, the crucial outcome with respect to our research question is the distribution of TFP growth over all sectors. We use the Harberger diagrams for both methods in order to check whether we observe similar distribution patterns as Inklaar and Timmer (2007). Specifically, 
we use these diagrams and the relative area underneath the Harberger diagram (RAH) to characterize how widespread ('yeast' - low RAH values) or localized ('mushroom' - high RAH values) productivity growth is. As shown in column one of Table 2, we see RAHs ranging from 0.49 to 0.85 for the analyzed countries when sectoral TFP measures are calculated following the growth accounting approach. Thus, the GA-TFPs are unevenly distributed across sectors. Looking at the GMPI-TFP (column 2), we see similar results. Countries like Portugal, Italy, Austria and Denmark show high RAHs greater than 0.5. Germany, Sweden and Finland have lower RAH, ranging from 0.39 to 0.46 . Hence, we also find a 'mushroom like' TFP growth pattern when applying GMPI. Yet, variation of RAH is greater regarding GMPI-TFPs than GA-TFPs. However, the growth patterns for the Netherlands (RAH 0.23) and the United Kingdom (RAH 0.25) are much more broad-based or 'yeasty'. Overall, as shown in Figure 2, the RAHs of the two TFP measures are positively correlated. With respect to the distribution of TFPs our results are in line with the findings of Inklaar and Timmer (2007) and Timmer et al. (2011). More specifically, the RAH of both the GA-TFPs and the GMPI-TFPs indicate an unequal distribution across sectors, or in other words, a 'mushroom like' TFP growth pattern.

Table 2: The Relative Areas under the Harberger (RAH) for both TFPs and the components of the GMPI-TFP, 1995-2005

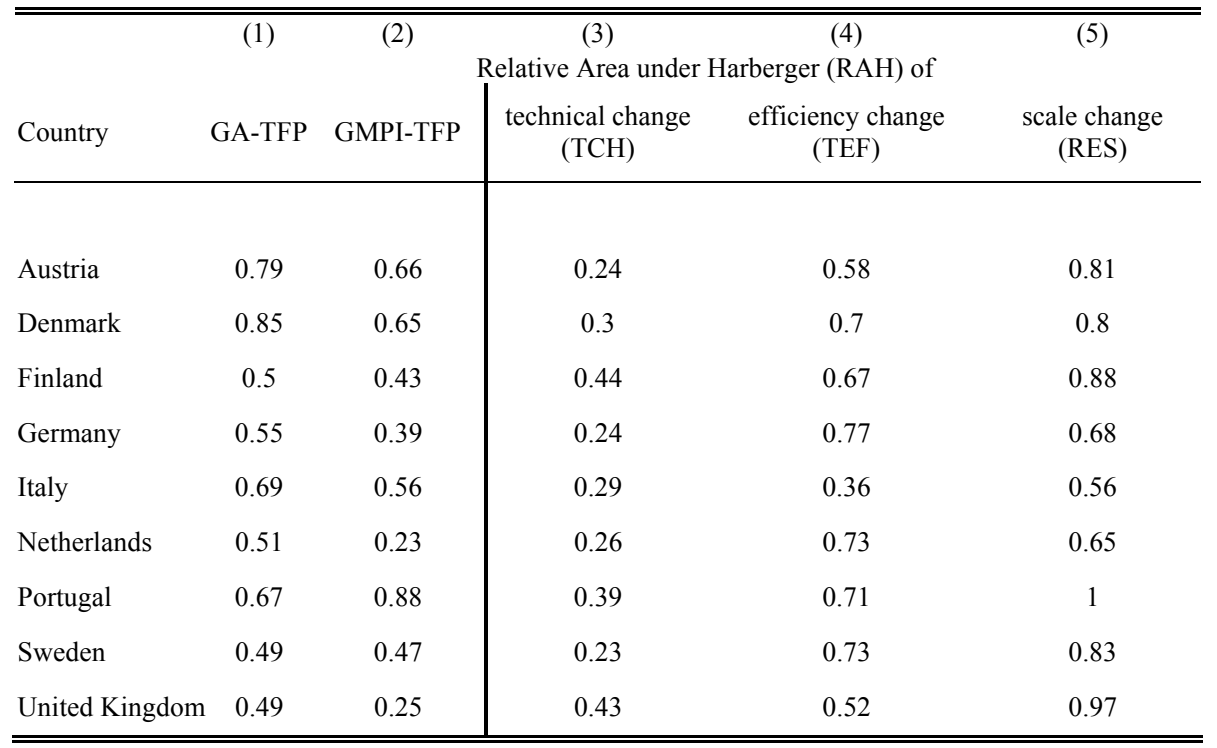

Source: EU KLEMS Database for GA-TFPs

Finding a similar result to that of Inklaar and Timmer (2007) with respect to the sectoral distribution of TFP, we proceed and look at the components of the GMPI-TFP in order to verify if technological progress is also as unevenly distributed. The results of the decomposition can be found in columns three to five of Table 1 . They show that the technological change, measured by the technology index (TCH), is the decisive driving force of TFP growth in all countries. This also holds true at the sector level. ${ }^{10}$ Yet, at the same time, almost all countries suffered efficiency losses as can be seen in column four. However, countries with efficiency im-

10 See Table A1 in the Appendix. 
provements, specifically Finland, the Netherlands and the United Kingdom, are also the countries with the highest TFP growth. Hence, for these countries the high TFP growth rates come not just from technical progress, but also from a more efficient use of inputs. Economies of scale, on the other hand, had a negative effect on TFP growth in all selected European countries, with the exception of Portugal.

Figure 2: Relative area under Harberger (RAH) for GA-TFP and GMPI-TFP ${ }^{11}$

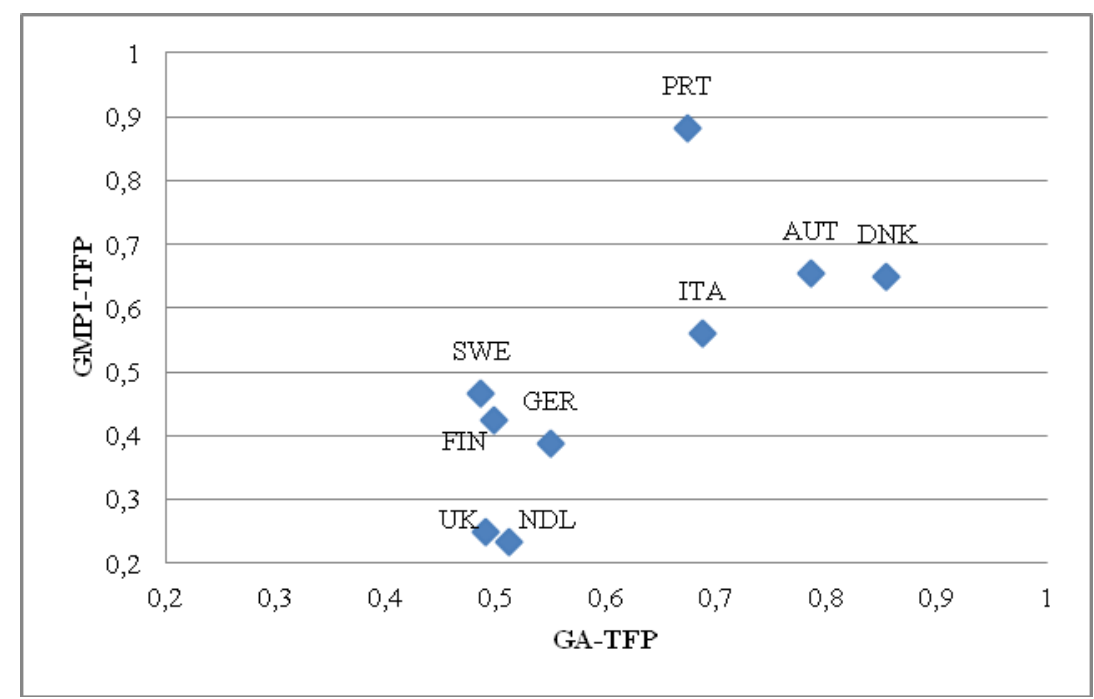

Source: EU KLEMS Database for GA-TFPs

To answer our central question on the sectoral concentration or distribution of technological change in Western Europe, we compare the RAH measures of the GMPI-TFPs and of its most important component, the technology index. We find that in almost all countries, the relative area under Harberger for the technology index (RAH TCH) is less than 0.3 and, therefore, lower than the RAH of the GMPI-TFP (see Table 2). It follows that technological progress is much more broad-based across sectors than TFP. To illustrate the entire spectrum of growth patterns, we show the Harberger diagrams of two countries. Portugal has the highest RAH indicator of the GMPI-TFP and therefore the most mushroom like sectoral growth pattern. The Netherlands show the lowest RAH indicator and therefore the most yeasty growth pattern. For these two countries we show two Harberger diagrams, one for the GMPI-TFP and one for the technological component TCH (Figure 3).

While the Harberger diagrams of the GMPI-TFP show clear differences in the concentration of growth contributions between both countries, the diagrams for the technology component (TCH) in Portugal and the Netherlands look quite similar. TCH diagrams are closer to diagonal than GMPI-TFP diagrams, signaling nearly equal contributions of technical change to growth across industries. As the relative area statistics already made clear, the RAHs of the technology component (TCH) are substantially lower than the RAHs of GMPI-TFP. Therefore our results for a range of Western European countries indicate that technical change, as

\footnotetext{
${ }^{11}$ Source of GA-TFPs is the EU KLEMS Database
} 
the main source of productivity growth, was fairly balanced over industries between 1995 and 2005. The only country for which this result was not found is the United Kingdom. Here the RAH of the technology component (0.43) is clearly higher than the RAH of the GMPI-TFP (0.25) (Table 2). In this country technological change between 1995 and 2005 was more 'mushroom' like and concentrated on a limited number of industries compared to other European countries (see Figure 4).

Figure 3: Harberger diagrams of GMPI-TFP and its components, 1995-2005 Portugal
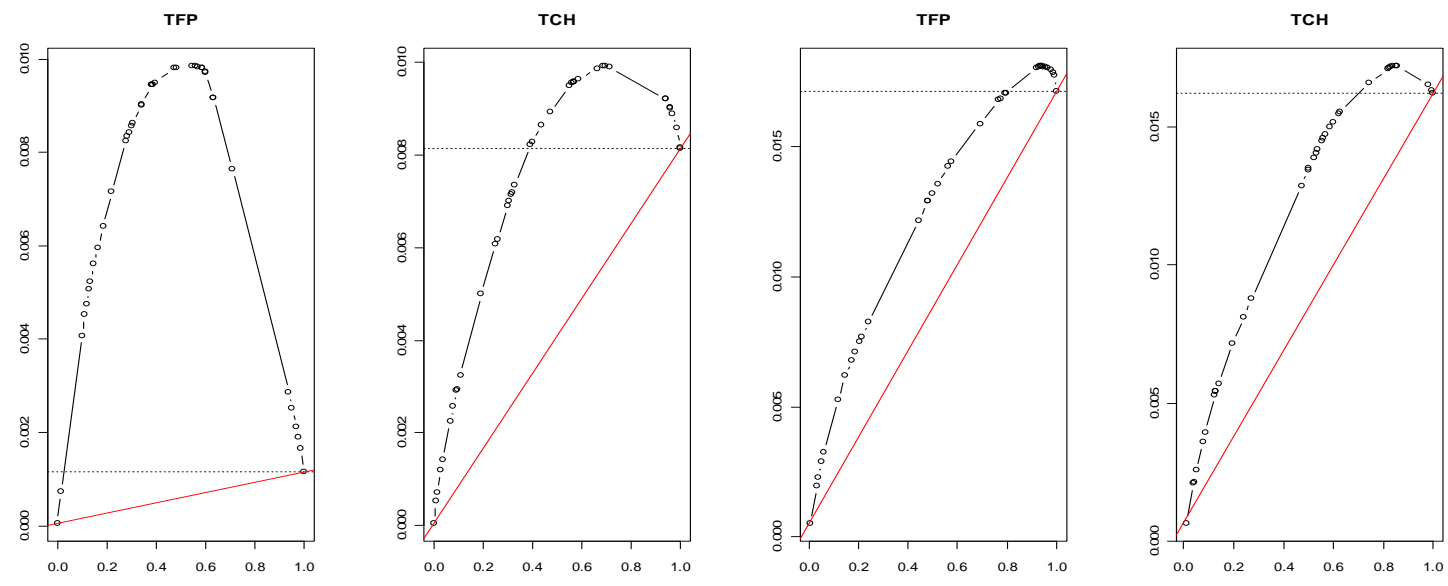

Figure 4: Harberger diagrams of GMPI-TFP and its components for the UK, 1995-2005
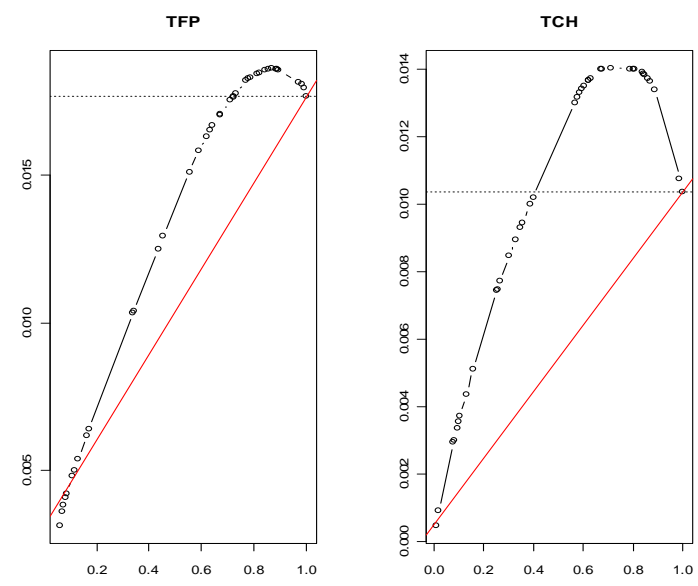

Our result shed new light on the results of Inklaar and Timmer (2007) and Timmer et al. (2011). Like them, we find 'mushroom-like' TFP growth pattern for European countries. But looking at technological change $(\mathrm{TCH})$, a more broad-based pattern is found. Overall, our analysis of productivity growth in Western Europe between 1995 and 2005 supports a vision of a broad-based technology driven growth process with little influence of sectoral differences. 


\section{Conclusion}

Previous research shows that TFP growth at the industry level is more broad based in AngloSaxon countries than in continental European countries. Given that, in the context of growth accounting approaches, TFP is taken as a proxy for technological progress, this finding suggests that technological progress in continental European countries it is confined to few sectors. Yet, TFP, measured in the tradition of growth accounting, is ultimately only a residual. Thus, it is an open question whether technological progress is really unevenly distributed across sectors within European nations, or whether other unknown factors cause the unequal distribution of TFPs.

The paper aims to address this question. To this end we use the Generalized Malmquist Productivity Index (GMPI), which allows for the decomposition of TFP into technological change, efficiency improvements and scale changes, as well as Harberger diagrams in order to visualize and measure the extent of sectoral divergences. The analysis is conducted for nine continental European countries.

The findings of the paper are as follows: First, our analysis confirms the presence of large differences in the sectoral patterns of TFP growth among European countries. In this respect, our results are in line with previous findings on TFP growth. Second, and in line with the literature using Malmquist approaches, decomposition reveals that the technology component explains large parts of TFP growth. However, as shown using the Harberger diagrams and the area under the Harberger, in almost all European countries technological progress is much more evenly distributed than TFP across sectors. Instead, we find stronger sectoral disparities in both efficiency improvements and scale changes than in the technology component. Hence, our results contradict the interpretation that sectorally concentrated TFP growth denotes sectorally concentrated technical progress, which is in fact much more widespread.

The only European country in which technological change between 1995 and 2005 was much more 'mushroom' like and more concentrated on a limited number of industries than the aggregated TFP is the United Kingdom. To test if the UK is actually the sole exception in this respect, the range of reviewed countries should be expanded in future research. In addition, in such cases it seems to be necessary to analyze the specific economic activities for example in relation to the position in the value chain. 


\section{Literature}

Arcelus, F.J., and P. Arozena. "Measuring sectroal productivity across time and across countries." European Journal of Operational Research, 1999: 254-266.

Ark, B. van, M. O'Mahony, and M.P. Timmer. "The Productivity Gap between Europe and the United States: Trends and Causes." Journal of Economic Perspectives, 2008: 2544.

Badunenko, O., D.J. Henderson, and V. Zelenyuk. "technological Change and Transition: Relative Contributions to Worldwide Growth During the 1990's." Oxford Bulletin in Economics and Statistics, 2008: 461-491.

Balassa, B. "The Purchasing-Power Parity Doctrine: A Reappraisal." Journal of Political, 1964: 584-596.

Caves, D.W., L.R. Christensen, and W.E. Diewert. "The Economic Theory of Index Numbers and the Measurement of Inputs, Outputs, and Productivity." Econometrica, 1982: 1393-1414.

Charnes, A., W.W. Cooper, and E. Rhodes. "Measuring the Inefficiency of Decision Making Units." European Journal of Operational Research, 1978: 429-444.

Coelli, T.J., D.S.P. Rao, C.J. O’Donnell, and G.E. Battese. An Introduction to Efficiency and Productivity Analysis. 2nd edition. New York: Springer, 2005.

Enflo, K., and P. Hjerststrand. "Relative Source of European Regional Productivity Convergence: A Bootstrap Frontier Approach." Regional Studies, 2009: 643-659.

Färe, R., S. Grosskopf, and D. Margaritis. "Productivity Growth and Convergence in the European Union." Journal of Productivity Analysis, 2006: 111-141.

Färe, R., S. Grosskopf, M. Norris, and Z. Zhang. "Productivity Growth, Technical Progress, and Efficiency Change in Industrialized Countries." American Economic Review, 1994: 66-83.

Farrell, M.J. "The measurement of productive efficiency." Journal of the Royal Statistical Society, Series A, 1957: 253-281.

Griffel-Tatje, E., and C.A.K. Lovell. "A note on the Malmquist productivity index." Economic Letters, 1995: 169-175.

-. "The source of productivity change in Spanish banking." European Journal of Operational Research, 1997: 364-380.

—. "A Generalized Malmquist productivity index." Sociedad de Estaistica e Investigacion Operativa Top, 1999: 81-101.

Harberger, A.C. "A Vision of the Growth Process." American Economic Review, 1998: 1-32.

Henderson, D.J., and R.R. Russell. "Human Capital and Convergence: A Production-Frontier Approach." International Economic Review, 2005: 1167-1205.

Inklaar, R., and M.P. Timmer. "Of Yeast and Mushrooms: Pattern of Industry-Level Productivity Growth." German Economic Review, 2007: 174-187.

Jorgenson, D.W., F.M. Gollop, and B.M. Fraumeni. Productivity and U.S. Economic Growth. Cambridge, MA: Harvard Economic Studies, 1987.

Krüger, J. "The global trends of total factor productivity: evidence from the nonparametric Malmquist index approach." Oxford Economic Papers, 2003: 265-286.

Kumar, S., and R.R. Russell. "Technolological Change, Technological Catch-up, and Capital Deepening: Relative Contribution to Growth and Convergence." American Econmic Review, 2002: 527-548.

Margaritis, D., R. Färe, and S. Grosskopf. "Productivity, convergence and policy: a study if OECD countries and industries." Journal of Productivity Analysis, 2007: 87-105. 
Maudos, J., J.M. Pastor, and L. Serrano. "Convergence in OECD countires: technical change, efficiency and productivity." Applied Economics, 2000: 757-765.

O'Mahony, M., and M.P. Timmer. "Output, Input and the Productivity Measure at the Industry Level: The EU KLEMS Database." The Economic Journal, 119, 2009: F374F403.

Roman, M. "The efficiency analysis applied for the evaluation of labour market policies: Study case for Romania." Munich Personal RePEc Archive, 20332, 2008.

Samuelson, P.A. "Theoretical Notes on Trade Problems." Review of Economic Studies, 1964: $145-154$.

Shephard, R.W. Cost and Production Function. New York: Princeton University Press, 1970.

Simar, L., and P.W. Wilson. "Statistical Inference in Nonparametric Frontier Models: Recent Developments and Perspectives." In The Measurement of Productive Efficiency Techniques and Application, by H. Fried, C.A.K. Lovell and S.S. Schmidt, 1-125. Oxford: Oxford University Press, 2005.

Timmer, M.P., R. Inklaar, M. O'Mahony, and B. van Ark. "Productivity and Economic Growth in Europe: A Comparative Industry Perspective." International Productivity Monitor, 2011: 3-23. 


\section{Appendix}

\section{Assets and drawbacks of the Malmquist Approach}

Inklaar and Timmer (2007) use the classical and wide spread TFP measure from the growth accounting approach of Jorgenson et al. (1987). Hence, TFP growth is the difference between the real output growth and a weighted growth of inputs. It could be seen as a residuum that explains that part of the output growth that cannot be explained by input growth. In the growth accounting framework this TFP growth is equal to technological progress. This approach, however, goes along with several restrictive assumptions as: (i) the functional form between inputs and outputs is defined ex ante and constant elasticities are assumed per year; (ii) technical change is Hicks-neutral; (iii) the production function is characterized by constant returns to scale; and (iv) no inefficiencies in no respects (neither allocative nor technical) of DMUs, peoples or sectors due to neoclassical optimizing behavior.

The main advantage of our method to measure TFP growth is the abandonment of these assumptions. Firstly, the data define the shape and the location of the frontier at each outputinput combination and no functional form is imposed. Hence, technical change does not need to be Hicks neutral, since the shape and location of the function at any $t+1$ doesn't depend on the functional form at $t$. Thirdly, we do not need to assume constant returns to scale. In fact we do not impose any assumption regarding returns to scale at all. If the production functions are described by variable returns to scale, the method will capture that as it would capture constant returns to scale. Finally we no longer assume that any DMU is acting efficiently at each point in time. We rather accept that some DMUs are more efficient than others at a certain moment and that each DMU is responsible for its steady, increasing or declining efficiency level.

However, calculating TFP growth using GMPI and DEA is not without drawbacks itself. Most of them are related to the DEA: (i) as a deterministic method its estimators are more heavily affected by outliers than estimators of parametric methods; (ii) the chosen dimension can result in an upward biased efficiency estimates if the sample does not have enough observations; and (iii) DEA - as a relative concept - judges each observations only compared to those in the sample.

However, these potential drawbacks only partly apply here. Since we used data based on official data collected by national statistical offices, our data base is controlled for outliers. The curse of dimensionality is taken into account by choosing a dimension such that we have three times as many observations as dimensions. ${ }^{12}$ Yet, the problem remains that our estimated distance functions describe relative distances to a frontier that is defined by the countries in the sample. Hence, the relative distances might be different if we would include all countries. However, this is not possible given the data constraints.

12 To avoid the curse of dimensionality and the resulting upward bias of DEA estimators, one should always have at least three times as many observations as dimensions (number of inputs + number of outputs) as a rule of thumb (Roman 2008). 
Table A1: GMPI and its components

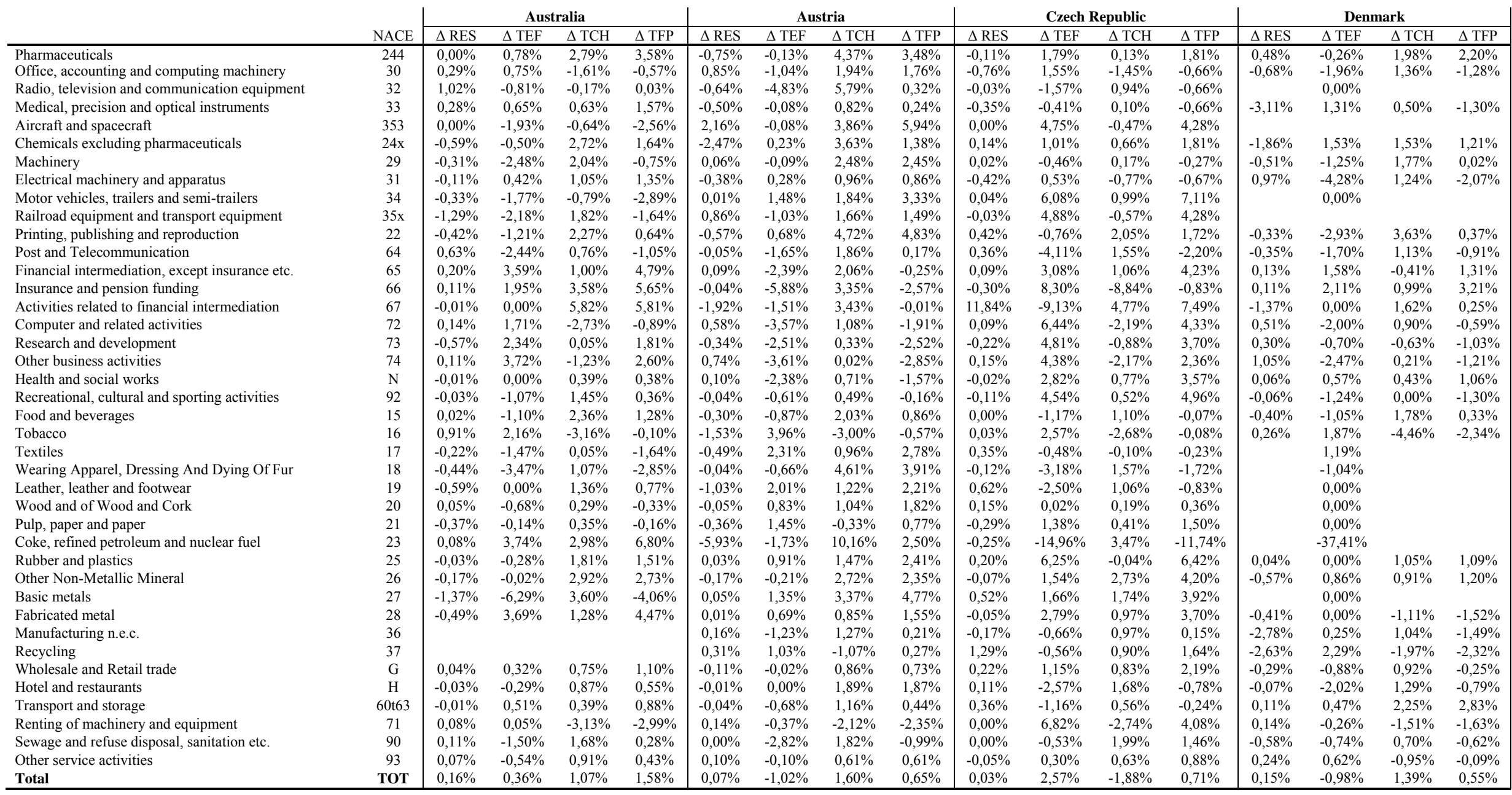




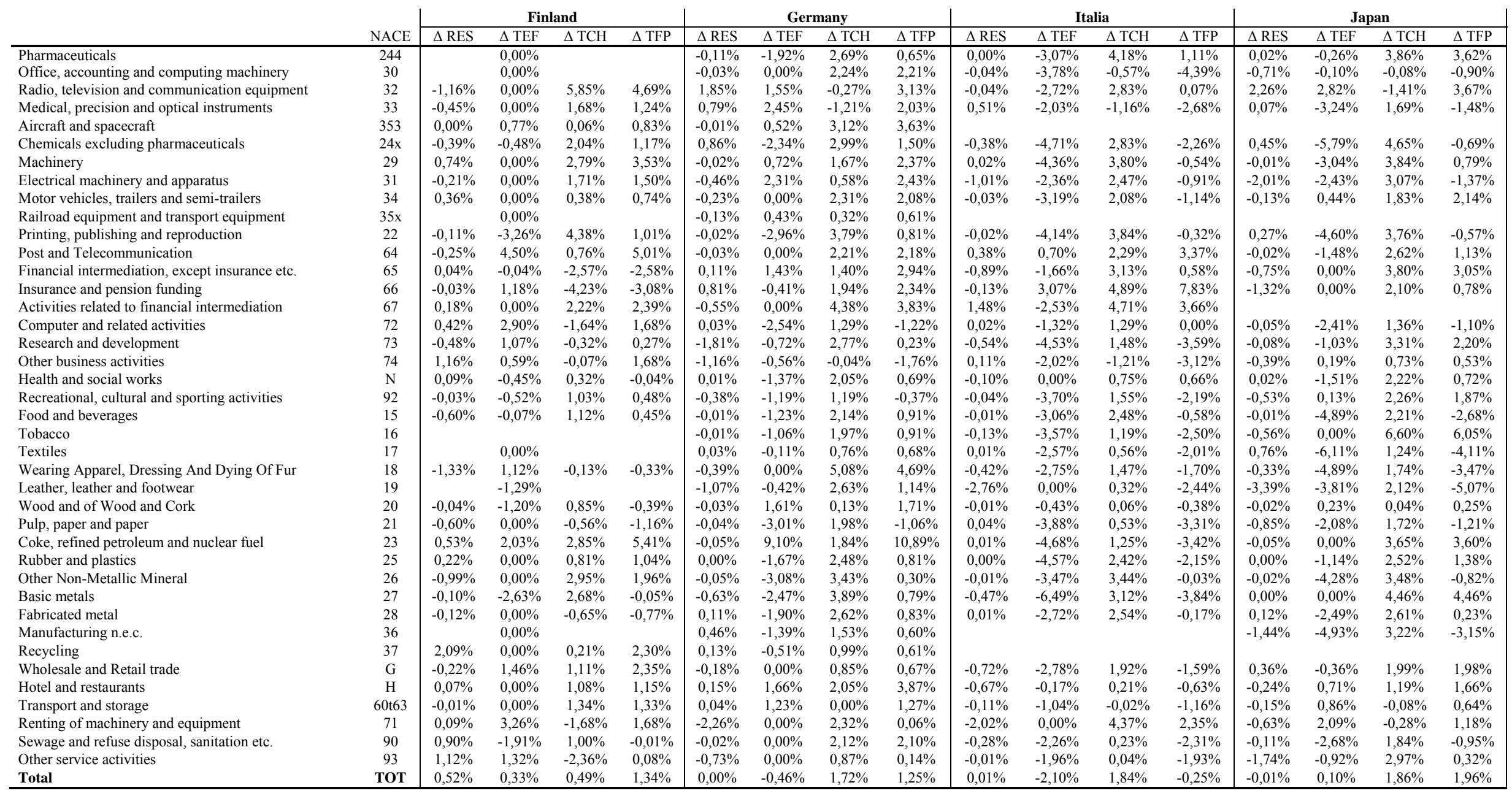




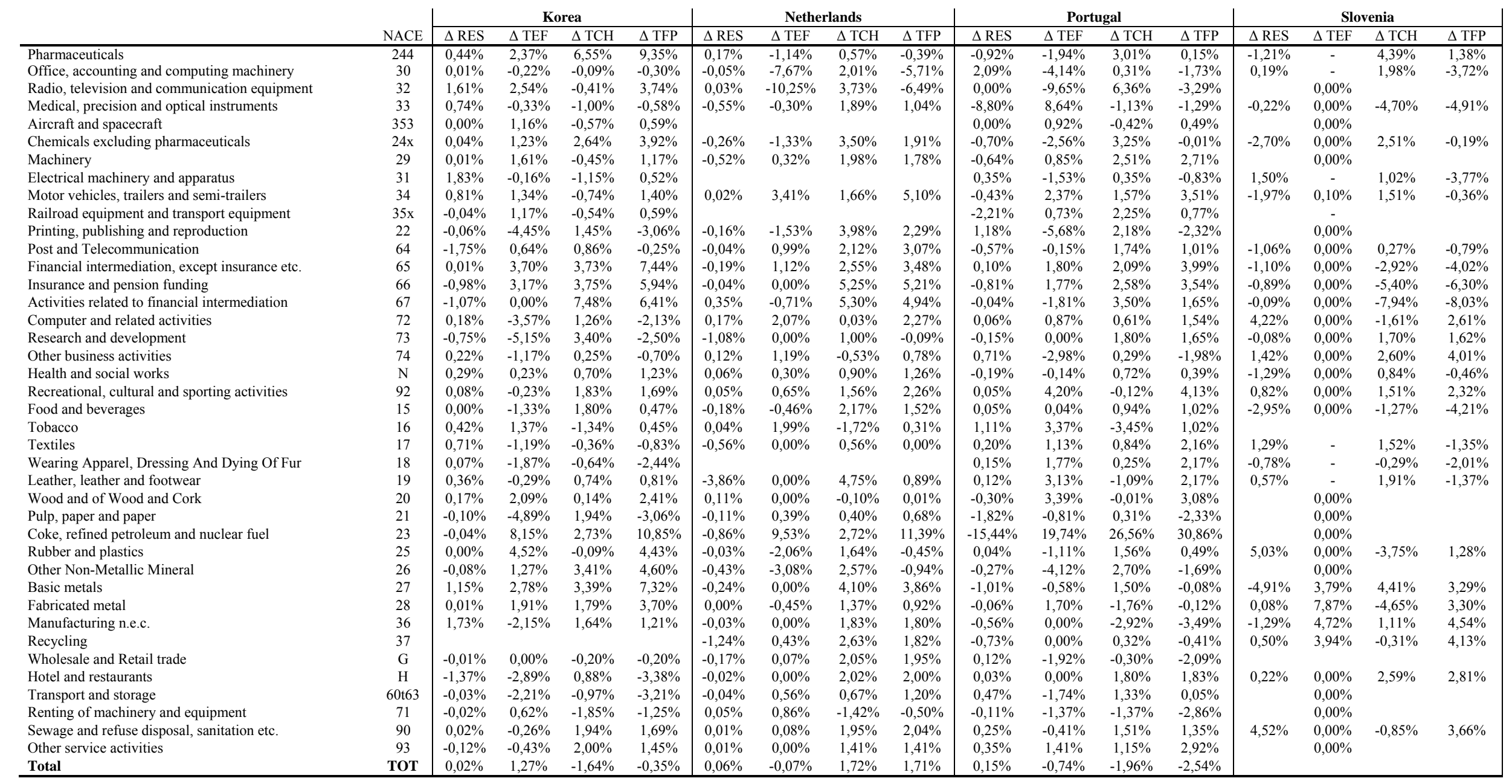




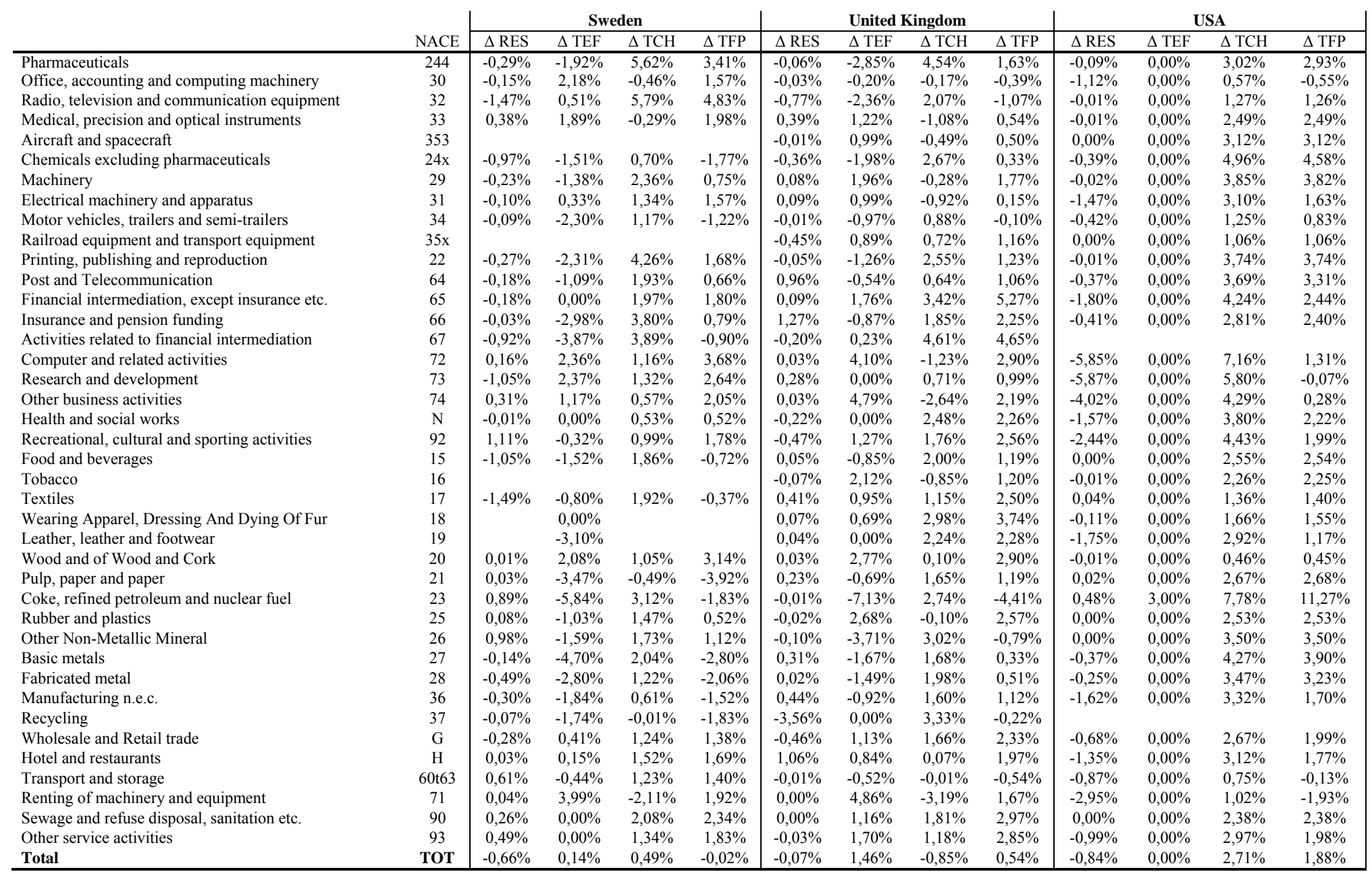

